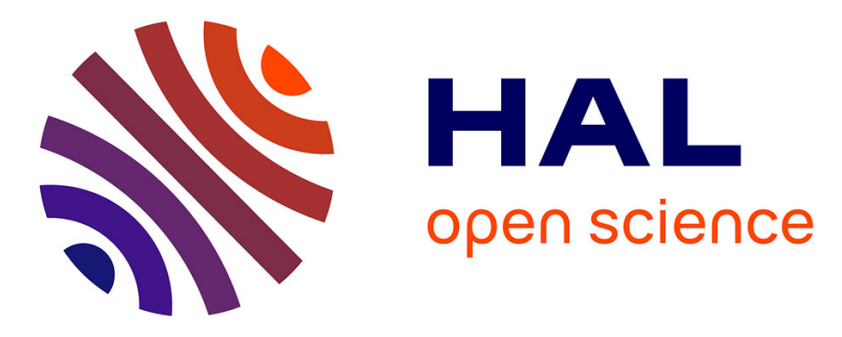

\title{
Deregulated expression of VHL mRNA variants in papillary thyroid cancer
}

Enke Baldini, Chiara Tuccilli, Yannick Arlot-Bonnemains, Frank Chesnel, Salvatore Sorrenti, Corrado de Vito, Antonio Catania, Eleonora d'Armiento, Alessandro Antonelli, Poupak Fallahi, et al.

\section{To cite this version:}

Enke Baldini, Chiara Tuccilli, Yannick Arlot-Bonnemains, Frank Chesnel, Salvatore Sorrenti, et al.. Deregulated expression of VHL mRNA variants in papillary thyroid cancer. Molecular and Cellular Endocrinology, 2017, 443, pp.121-127. 10.1016/j.mce.2017.01.019 . hal-01478813

\section{HAL Id: hal-01478813 https://hal-univ-rennes1.archives-ouvertes.fr/hal-01478813}

Submitted on 1 Jun 2017

HAL is a multi-disciplinary open access archive for the deposit and dissemination of scientific research documents, whether they are published or not. The documents may come from teaching and research institutions in France or abroad, or from public or private research centers.
L'archive ouverte pluridisciplinaire HAL, est destinée au dépôt et à la diffusion de documents scientifiques de niveau recherche, publiés ou non, émanant des établissements d'enseignement et de recherche français ou étrangers, des laboratoires publics ou privés. 


\section{Deregulated expression of VHL mRNA variants in papillary thyroid cancer}

Enke Baldini, ${ }^{1}$ Chiara Tuccilli, ${ }^{2}$ Yannick Arlot-Bonnemains, ${ }^{3}$ Frank Chesnel, ${ }^{3}$ Salvatore Sorrenti, ${ }^{1}$

Corrado De Vito, ${ }^{4}$ Antonio Catania, ${ }^{1}$ Eleonora D'Armiento, ${ }^{2}$ Alessandro Antonelli, ${ }^{5}$ Poupak Fallahi, ${ }^{5}$ Sara Watutantrige-Fernando, ${ }^{6}$ Francesco Tartaglia, ${ }^{1}$ Susi Barollo, ${ }^{6}$ Caterina Mian, ${ }^{6}$ Marco

Bononi, ${ }^{7}$ Stefano Arceri, ${ }^{1}$ Domenico Mascagni, ${ }^{1}$ Massimo Vergine, ${ }^{1}$ Daniele Pironi, ${ }^{1}$ Massimo Monti, ${ }^{1}$ Angelo Filippini, ${ }^{1}$ Salvatore Ulisse* ${ }^{1}$

${ }^{1}$ Department of Surgical Sciences, "Sapienza" University of Rome, Italy; ${ }^{2}$ Department of Experimental Medicine, "Sapienza" University of Rome, Italy; ${ }^{3}$ CNRS-UMR 6290 (IGDR) Université Rennes 1, Rennes, France; ${ }^{4}$ Department of Public Health and Infectious Diseases, "Sapienza" University, Rome, Italy; ${ }^{5}$ Department of Clinical and Experimental Medicine, University of Pisa, Italy; ${ }^{6}$ Department of Medicine, University of Padua, Italy; ${ }^{7}$ Department of Surgery “Pietro Valdoni”, “Sapienza” University of Rome, Italy.

\section{*Corresponding author:}

Prof. Salvatore Ulisse Department of Surgical Sciences "Sapienza" University of Rome Viale Regina Elena, 324 00161-Rome - Italy email: salvatore.ulisse@uniroma1.it 


\begin{abstract}
Recent findings demonstrated that a subset of papillary thyroid cancers (PTCs) is characterized by reduced expression of the von Hippel-Lindau ( $V H L)$ tumor suppressor gene, and that lowest levels associated with more aggressive PTCs. In the present study, the levels of the two VHL mRNA splicing variants, VHL-213 (V1) and VHL-172 (V2), were measured in a series of 96 PTC and corresponding normal matched tissues by means of quantitative RT-PCR. Variations in the mRNA levels were correlated with patients' clinicopathological parameters and disease-free interval (DFI). The analysis of VHL mRNA in tumor tissues, compared to normal matched tissues, revealed that its expression was either up- or down-regulated in the majority of PTC. In particular, V1 and V2 mRNA levels were altered, respectively, in $78(81.3 \%)$ and $65(67.7 \%)$ out of the 96 PTCs analyzed. A significant positive correlation between the two mRNA variants was observed $(\mathrm{p}<0.001)$. Univariate analysis documented the lack of association between each variant and clinicopathological parameters such as age, tumor size, histology, TNM stage, lymph node metastases, and BRAF mutational status. However, a strong correlation was found between altered V1 or V2 mRNA levels and DFI. Multivariate regression analysis indicated higher V1 mRNA values, along with lymph node metastases at diagnosis, as independent prognostic factors predicting DFI. In conclusion, the data reported demonstrate that $V H L$ gene expression is deregulated in the majority of PTC tissues. Of particular interest is the apparent protective role exerted by VHL transcripts against PTC recurrences.
\end{abstract}

Keywords: Papillary thyroid cancer; VHL; Gene expression; Prognosis; Biomarkers. 


\section{Introduction}

The von Hippel-Lindau (VHL) gene, located on chromosome 3p25-p26, consists of 3 exons (Latif et al. 1993). Two different VHL mRNAs are generated because of differential splicing: the variant 1 (V1), including all three exons, and the variant 2 (V2), lacking exon 2 (Iliopolus et. 1998; Gnarra et al. 1994; Richards et al. 1996). From the V1 mRNA, two VHL protein (pVHL) isoforms are synthesized due to alternate initiation sites of translation; the $\mathrm{pVHL}_{213}$, of about $30 \mathrm{kDa}$ and containing 213 amino acids, and the $\mathrm{pVHL}_{160}$, of about $19 \mathrm{kDa}$ and containing 160 amino acids (Schoenfeld et al. 1998). The V2 mRNA variant encodes a protein of 172 amino acids lacking an amino-terminal pentameric acid repeat ( $\beta$-domain), with a predicted molecular weight of about 19 $\mathrm{kDa}\left(\mathrm{pVHL}_{172}\right)($ Chesnel et al. 2015).

The VHL gene is widely expressed in human tissues and acts as a tumor suppressor gene (Los et al. 1996). Loss-of-function mutations cause the so-called VHL disease, an autosomal dominant disorder characterized by retinal angioma, cerebellar and spinal hemangioblastomas, clear-cell renal cell carcinoma (ccRCC), pheochromocytoma and pancreatic neuroendocrine tumor (Maher et al. 2011). Besides, a number of sporadic cancers, including ccRCC, are strongly associated with VHL reduced expression and/or loss-of-function mutations (Gnarra et al. 1994; Cassol and Mete, 2015). The best characterized pVHL function is ubiquitination followed by proteasome degradation of target proteins (Robinson and Ohh, 2014). In particular, the pVHL forms a multiprotein complex with elongins $\mathrm{B}$ and $\mathrm{C}$, cullin 2 and Rbx-1, which functions as a ubiquitinligating enzyme (E3 ligase). Within the complex pVHL is responsible for recognition of substrates, among which the members of the hypoxia-inducible factor $\alpha$ (HIF $\alpha)$ family (Robinson and Ohh, 2014). In complex with HIF $\beta$, HIF $\alpha$ act as transcription factors enhancing the expression of a variety of genes involved in the adaptive response to hypoxic condition and tumor progression as well, such as genes that promote neoangiogenesis (e.g. vascular endothelial growth factor, VEGF), energy metabolism (e.g. glucose transporter 1, GLUT1), erythropoiesis (e.g. erythropoietin, EPO), and cell survival (e.g. transforming growth factor- $\alpha$, TGF- $\alpha$ ) (Robinson and Ohh, 2014; Balamurugan, 2016). In addition, VHL has been shown to affect several hypoxia-independent cellular functions, including extracellular matrix formation, spindle microtubule stability, cilia formation, epithelial-to-mesenchymal (EMT) transition, cell proliferation, apoptosis and DNA damage response (Robinson and Ohh, 2014).

The pVHL region interacting with the elongins and Cul-2, named BC box, is coded by the third exon, thus all pVHL isoforms are able to form the E3 ligase complex (UniProtKB - P40337). However, the binding with HIF $\alpha$ occurs via the $\beta$-domain, which is missing in the $\mathrm{pVHL}_{172}$ 
(Bonicalzi et al. 2001). Such domain is also essential for VHL interaction with the chaperonincontaining t-complex polypeptide 1 (CCT), a cytosolic molecular chaperone that assists in the folding of actin, tubulin and other cytosolic proteins. Even if the physiological role of $\mathrm{pVHL}_{172}$ remains to be elucidated, it might be supposed that this isoform behaves, at least partially, as a $\mathrm{VHL}_{213}$ antagonist, and possibly is endowed with new functions.

Some reports suggested that pVHL could play a role also in the progression of epithelial thyroid cancer (TC) (The Cancer Genome Atlas Research Network, 2014; Stanojevic et al. 2015; Hinze et al. 2000; Hunt et al. 2003). The latter represents the most common endocrine malignancy accounting for roughly $1 \%$ of all human cancers, and its incidence has been increasing over the last decades mainly due to the improved ability to diagnose malignant transformation in small nonpalpable thyroid nodules (Jemal et al. 2009; Davies and Welch, 2006; Kinder, 2003; Patel and Shaha, 2006; Pasieka, 2003). More than $90 \%$ of TC are differentiated thyroid carcinomas (DTC), $70-80 \%$ of which are represented by the papillary (PTC), and the remaining by the follicular (FTC) histotype (Nikiforov et al. 2009). Although derived from the same cell type, the DTC show specific histological features, biological behavior and degree of differentiation because of different genetic alterations (The Cancer Genome Atlas Research Network, 2014; Nikiforov et al. 2009). Among the somatic activating mutations, those of genes involved in the mitogen activated protein kinase (MAPK) signaling pathway, e.g. Ras, BRAF and RET/PTC rearrangements, are held responsible for the majority of PTC (The Cancer Genome Atlas Research Network, 2014; Nikiforov et al. 2009). Treatment of patients includes total thyroidectomy followed, if necessary, by ${ }^{131}$ I therapy. The prognosis is generally favorable, with a 10-year-survival rate of approximately $90 \%$. Nevertheless, nearby $20 \%$ of patients have disease recurrences and tumor-related deaths (EustatiaRutten et al. 2006). The stratification and prognosis of patients depends on clinicopathological variables such as age, tumor size, histology, lymph nodal or distant metastases (Eustatia-Rutten et al. 2006; Gospodarowicz et al. 2001; Passler et al. 2004; Castagna et al. 2011). These parameters, however, are capable of providing only a rough prediction of the disease outcome placing patients with very different disease-specific progression and survival times within the same risk group. Similarly, they fail to predict the risk of cancer relapse. Therefore, the identification of new prognostic molecular biomarkers able to testify tumor aggressiveness is required (Handkiewicz et al. 2010; Baldini et al. 2012; Ulisse et al. 2011).

Although, to date, no loss-of-function mutations of the VHL gene in PTC tissues have been described, recent studies demonstrated that a subset of PTCs was characterized by low levels of VHL mRNA, which associated with more aggressive PTCs (The Cancer Genome Atlas Research Network, 2014; Stanojevic et al. 2015). 
In the present work, we measured the expression of the $V H L$ gene, at mRNA level, in a case-study of 96 PTC tissues compared with their normal matched counterparts, and we evaluated the correlation of the $V H L$ expression changes with clinicopathological parameters and disease-free interval.

\section{Patients and Methods}

\section{Tissue samples, histology and patient's staging}

Normal and matched tumor thyroid tissues were obtained from surgical specimens of 96 patients (19 males and 77 females, age range 11-83 yr, median $44 \mathrm{yr}$ ) who underwent total thyroidectomy for PTC at the Department of Surgical Sciences, "Sapienza" University of Rome (39 patients) or at the Department of Medicine, University of Padua (57 patients). All patients gave their informed consent, and the study was approved by the local ethical committee (Protocol No. 2615). Tissue samples were collected, frozen in liquid nitrogen and stored at $-80{ }^{\circ} \mathrm{C}$. Of the 96 PTC patients, 72 exhibited classical, 17 follicular, 3 tall cell and 4 oncocytic variants. The histological diagnoses were made independently by two different histopathologists according to the World Health Organization classification (Hedinger et al. 1989). At the time of surgery lymph node metastases were found in 39 patients. Following TNM staging, 62 patients were at stage I, 1 at stage II, 27 at stage III and 6 at stage IV. Approximately 40 to 50 days later, all the patients underwent radioiodine treatment followed by thyroid hormone replacement therapy. To ascertain their disease-free condition, 4 to 5 months later all the patients underwent neck ultrasound and serum $\mathrm{Tg}$ measurement. Recurrences were diagnosed by measurement of serum Tg levels either in basal conditions or following recombinant human TSH stimulation; FNA cytology and/or Tg determination in the FNA wash-out from lymph nodes; ${ }^{131}$ I whole body scan; histological analysis following surgical resection of the lesion. The follow-up included 80 patients (mean $57.9 \pm 36.0$ months, range 5-141 months), 54 of whom were at TNM stage I. During the follow-up 17 recurrences were recorded.

\section{Determination of BRAF ${ }^{V 600 E}$ mutation}

Genomic DNA was extracted from the frozen tumor tissues using the DNeasy Blood and Tissues kit (QIAGEN, Milan, Italy) according to the manufacturer's protocol. The BRAF status of exon 15 was assessed by both direct sequencing and mutant allele-specific PCR amplification for the T to A 
substitution at nucleotide 1799 (V600E), using the procedure previously described (Barollo et al. 2010).

\section{Extraction of $m R N A$ and quantitative RT-PCR}

Frozen normal and tumor thyroid tissues were homogenized with the ultra-turrax, and total RNA extracted applying the acid guanidinium thiocyanate-phenol-chloroform method (Chomczynsky and Sacchi, 1987). The first cDNA strand was synthesized from $5 \mu \mathrm{g}$ of RNA with M-MLV reverse transcriptase and anchored oligo(dT)23 primers (Sigma Chemicals Co.). Parallel controls for DNA contamination were carried out omitting the reverse transcriptase. The templates obtained were used for quantitative PCR amplifications of the VHL mRNA variants 1 and 2 , and three different housekeeping genes (GAPDH, RPL13A and SDHA) employing the LightCycler instrument (Roche Diagnostics, Mannheim, Germany), the SYBR Premix Ex Taq II (TliRNase H Plus) (Takara, Otsu, Shiga, Japan) and specific primers listed in Table 1.

Table 1. Sequences, genomic positions, and amplicon sizes of the primers used in qRT-PCR for the target and reference genes. VHL, von Hippel-Lindau; GAPDH, glyceraldehyde-3phosphate dehydrogenase; RPL13A, ribosomal protein L13a; SDHA, succinate dehydrogenase complex, subunit A; V1, VHL variant 1; V2, VHL variant 2.

\begin{tabular}{clcc}
\multicolumn{1}{c}{ Gene } & \multicolumn{1}{c}{ Primers } & Exon & Size (bp) \\
\hline \multirow{2}{*}{ VHL-213 (V1) } & Forward 5'-GACACACGATGGGCTTCTG-3' & 2 & \multirow{2}{*}{ ' } \\
& Reverse 5'-TGACGATGTCCAGTCTCCTG-3' & 3 & \\
\hline \multirow{2}{*}{ VHL-172 (V2) $)$} & Forward 5'-GCATCCACAGCTACCGAGTGTA-3' & $1-3$ & \multirow{2}{*}{99} \\
& Reverse 5'-TGACGATGTCCAGTCTCCTG-3' & 3 & \\
\hline \multirow{2}{*}{ GAPDH } & Forward 5'-ATCATCAGCAATGCCTCCTG-3' & $6-7$ & \multirow{2}{*}{136} \\
& Reverse 5'-GGCCATCCACAGTCTTCTG-3' & 8 & \\
\hline \multirow{2}{*}{ RPL13A } & Forward 5'-ACCGTGCGAGGTATGCTG-3' & $4-5$ & \multirow{2}{*}{148} \\
& Reverse 5'-TAGGCTTCAGACGCACGAC-3' & 6 & \\
\hline \multirow{2}{*}{ SDHA } & Forward 5'-GCATAAGAACATCGGAACTGC-3' & 12 & \multirow{2}{*}{147} \\
& Reverse 5'-GGTCGAACGTCTTCAGGTG-3' & 13 & \\
\hline
\end{tabular}


Amplicon specificities were checked by automated DNA sequencing (Bio-Fab Research, Rome, Italy), evaluation of melting temperatures, and electrophoresis on $2 \%$ agarose gel containing ethidium bromide. For the relative quantification of gene expression, standard curves were made with five-fold dilutions of mixed cDNAs from human thyroid tissues for all reference and target genes. Calculation of data was performed by the Relative Expression Software Tool (REST 2009) using a normalization factor computed as geometric media of the 3 reference genes, as previously described (Vandesompele et al. 2002; Ulisse et al. 2012). The fold change of VHL gene expression for each tumor sample was referred to its normal counterpart.

For the absolute quantification of VHL V1 and V2 mRNAs, two standard curves were created with five-fold dilutions of known amounts of two different BamHI-linearized plasmids, each containing the sequence of a VHL variant. Specifically, pCDNA3.1-FlagHA-VHL213 or -VHL172 plasmids were generated by inserting a $639 \mathrm{bp}$ or a $516 \mathrm{bp}$ BamHI-XhoI fragment (coding for human VHL open reading frames digested out of pET21-VHL213 or pET21-VHL172 plasmids, respectively) (Chesnel et al. 2015) in frame to the 3'-end of the Flag-HA sequence of pcDNA3-FlagHA plasmid (a kind gift from Dr S. Rouquier, Toulouse, France). Constructs were confirmed by Sanger sequencing, amplified in NEB5alpha bacteria (New England Biolabs, Evry, France) and purified using the Nucleobond Endofree plasmid purification kit (Macherey Nagel, Hoerdt, France). Copy numbers of the VHL mRNA variants were estimated by interpolation of the crossing points obtained for the tissue samples on these standard curves, and quantitative ratios VHL V1/V2 were calculated for normal and tumor tissue of each patient.

\section{Statistical analysis}

First, the Shapiro-Wilk test was used to check whether the mRNA data were normally distributed, and they were not. Thus, the non-parametric Mann-Whitney U-test was used to calculate the statistical significance of differences in the expression levels of VHL mRNA V1 and V2 in female vs male patients; in classical PTC variant $v s$ other variants; in $\mathrm{BRAF}^{\mathrm{V} 600 \mathrm{E}}$ mutated $v s$ wild type PTC; in metastatic (N1) vs non-metastatic (N0) PTC; in T1-2 vs T3-4 tumor sizes; in TNM I-II vs III-IV stages; in presence or absence of recurrence. The correlation between V1 and V2 mRNAs, and between each of them and patient's age was evaluated by the Spearman's Rho test.

The VHL V1/V2 mRNA ratio comparison between normal and PTC tissues was performed with the Wilcoxon signed-rank test. To assess the independent association of patient's age, gender, tumor size, histological variants, BRAF status, lymph node metastases, stage and VHL mRNA variants with recurrences, the Cox regression with backward analysis was used. The impact of V1 or V2 expression on DFI was assessed by the Kaplan-Meier analysis combined with Mantel-Cox log-rank. 
For the latter, values were classified based on the following criteria: fold change $>1.2$ as "increased"; fold change $<0.8$ as "decreased"; $0.8 \leq$ fold change $\leq 1.2$ as unvaried. All the statistical analyses were carried out with the SPSS software (IBM, Armonk, NY, USA), and the results were considered significantly different if $\mathrm{p}$ values were lower than 0.05 .

\section{Results}

VHL gene expression in papillary thyroid cancer (PTC) tissues

The analyses of V1 and V2 mRNA levels in PTC tissues, compared to their normal matched tissues, revealed that V1 mRNA was deregulated in 78 out of 96 PTC $(81.3 \%)$, with an increase in 36 and a decrease in 42 cases (Figure 1A). The V2 mRNA was altered in 65 out of 96 PTC (67.7\%), being up-regulated in 24 and down-regulated in 41 cases (Figure 1B). As reported in Figure 1C, mRNA levels of the two VHL variants positively correlated to each other $(\mathrm{p}<0.001)$. 

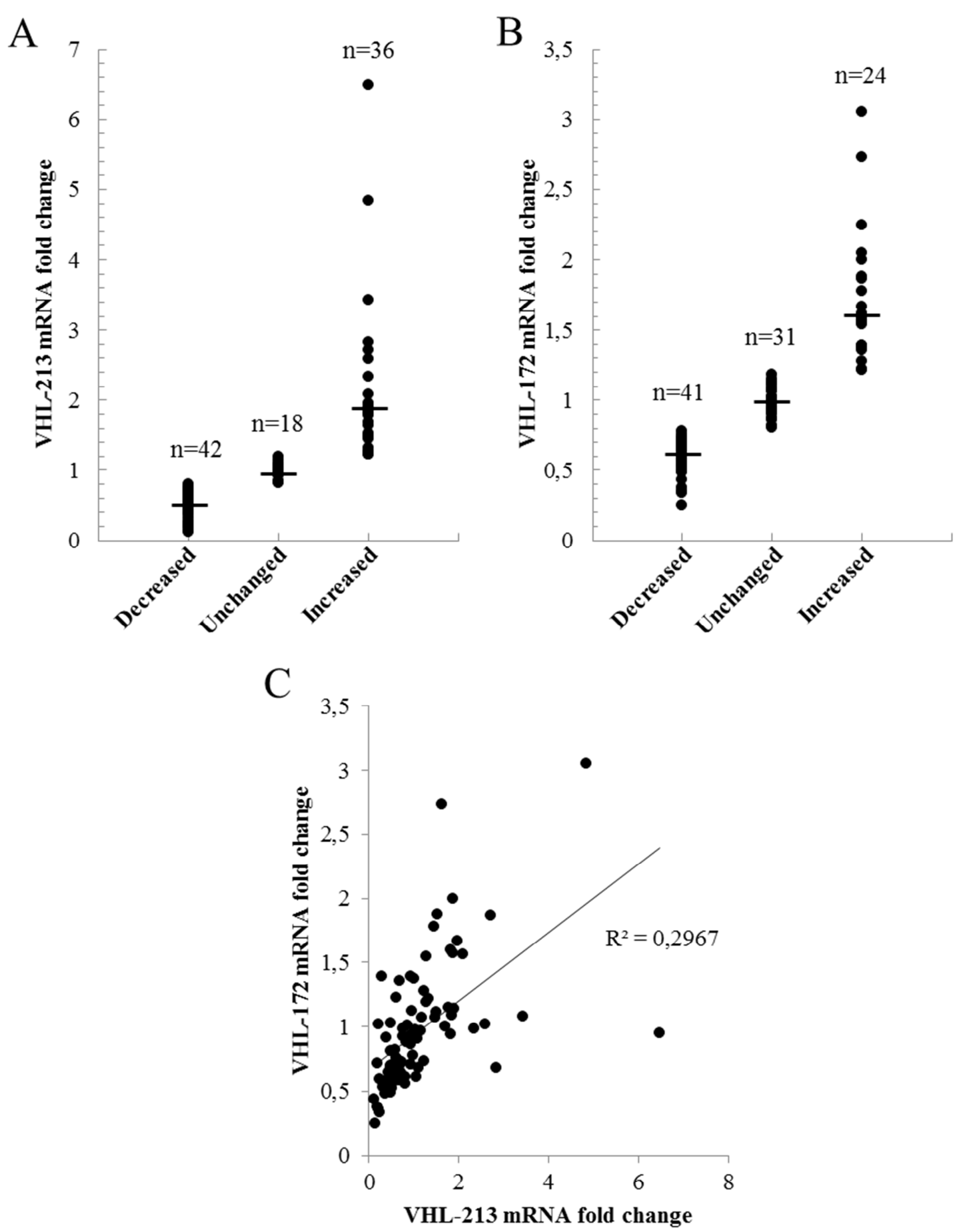

Figure 1: Relative expression levels of the VHL mRNA splicing variants in 96 PTC tissues. A) and B) Variations of the V1 and V2 mRNAs, respectively. The fold changes were calculated considering the mRNA values of normal matched thyroid tissues equal to one. The statistical evaluation of the data was performed with the non-parametric Mann-Whitney test. The small bars in the graph indicate the median values. C) Correlation analysis of V1 and V2 mRNAs in PTC tissues. The data were evaluated by applying the Rho Spearman test. 
Absolute quantification of the V1 and V2 mRNA copy number for each tumor and normal matched tissue showed that V1 mRNA copy number was higher compared to the V2 mRNA, with a median V1/V2 ratio of 3.95 in normal tissues (Figure 2). This ratio did not change significantly in PTC tissues, the median being $3.52(\mathrm{p}=0.655)$.

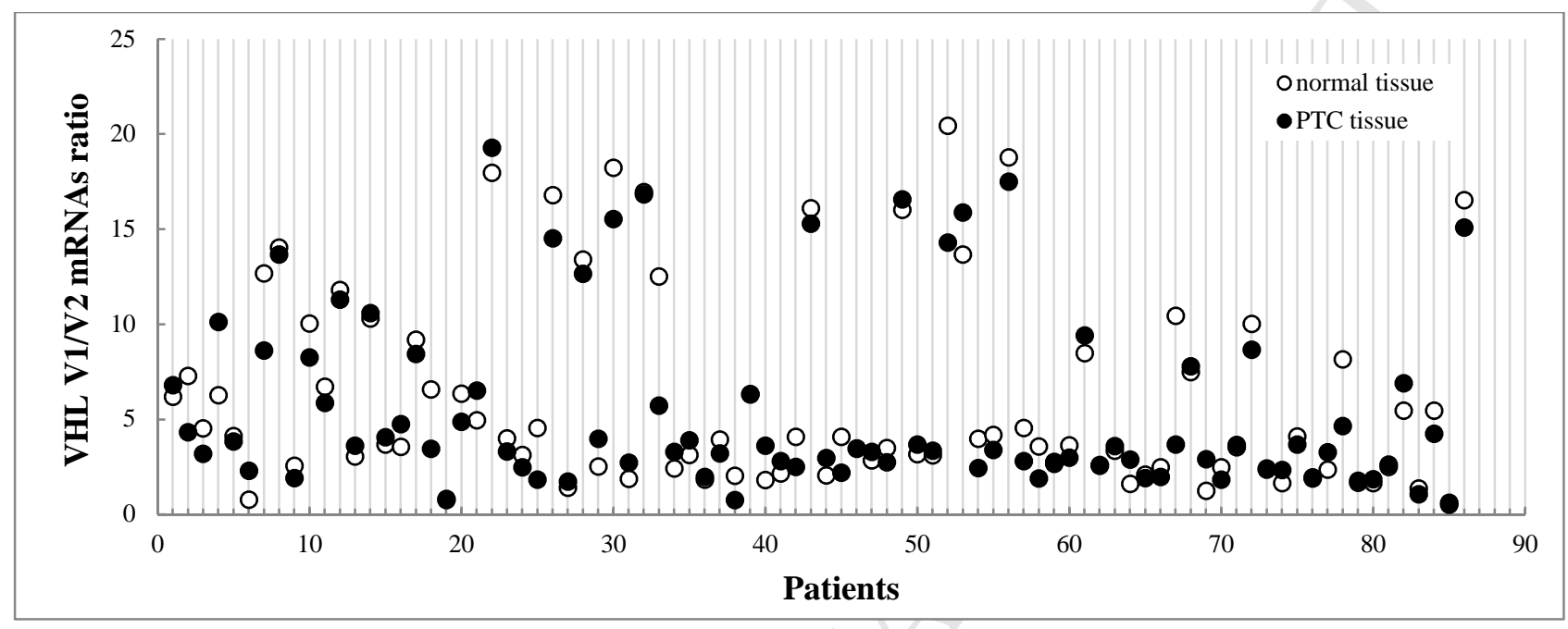

Figure 2: VHL V1/V2 mRNAs ratio in PTC and normal matched tissues.

$B R A F^{V 600 E}$ mutation and VHL expression in PTC tissues

To assess the effect of BRAF ${ }^{\mathrm{V} 600 \mathrm{E}}$ mutation on VHL expression, we analyzed the V1 and V2 mRNA levels in 76 PTC tissues for which the analysis of BRAF gene status was available. Of these, 37 PTC $(48.7 \%)$ harbored the $\mathrm{BRAF}^{\mathrm{V} 600 \mathrm{E}}$ mutation while 39 (51.3\%) had the wild type BRAF. The results, reported in table 2, showed that the $\mathrm{BRAF}^{\mathrm{V} 600 \mathrm{E}}$ mutation did not affect $V H L$ gene transcription in PTC tissues.

Prognostic relevance of VHL expression in PTC patients.

Among the clinicopathological parameters analyzed, a significant association emerged between tumor relapse and low levels of V2, and a similar trend ( $\mathrm{p}=0.057)$, was recorded for V1 (Table 2). Moreover, increased V1 mRNA levels were found in male PTC tissues compared to the female ones $(\mathrm{p}=0.03)$. Cox regression analysis indicated that, among all the parameters considered, the presence of lymph node metastases at diagnosis represented a risk factor for tumor recurrences (Hazard Ratio, HR 9.37, $\mathrm{p}=0.003$ ), while patients with increased V1 levels had a reduced risk of tumor recurrences (HR 0.18, p=0.025). Kaplan-Mayer analysis demonstrated a significant correlation of both V1 and V2 mRNA levels with patients' disease-free interval (DFI). In figure 3, panels A and 
$\mathrm{B}$, the DFI is represented for patients grouped in three categories based on the mRNA fold changes: increased, unvaried and decreased. Looking at the graphic of V1 mRNA, the trends for patients with unvaried and decreased values were very similar, so they were grouped together and compared against PTC patients with increased values. As shown in figure 3 (panel C), the returned p-value of log-rank test was 0.007. Regarding the V2 mRNA, PTC patients with unvaried or increased values had analogous DFI profiles (figure 3, panel B). When the latter were grouped together and compared to patients with decreased V2 mRNA levels, a significant difference $(p=0.025)$ emerged (figure 3, panel D). 
Table 2. Univariate statistical analysis of VHL mRNA variants, and PTC patient's characteristics and high-risk clinicopathological features.

\begin{tabular}{|c|c|c|c|c|}
\hline & VHL-213 (V1) & $p$ value & VHL-172 (V2) & $p$ value \\
\hline \multicolumn{5}{|l|}{ Gender } \\
\hline Male $(n=19)$ & $1.48(0.19-2.84)$ & \multirow[t]{2}{*}{0.030} & $1.07(0.38-2.73)$ & \multirow[t]{2}{*}{0.151} \\
\hline Female $(n=77)$ & $0.81(0.12-6.48)$ & & $0.91(0.25-3.05)$ & \\
\hline Age (years) & Corr. Coeff. 0.004 & 0.971 & Corr. Coeff. -0.015 & 0.885 \\
\hline \multicolumn{4}{|l|}{ Histology } & \multirow{3}{*}{0.467} \\
\hline Classical variant $(\mathrm{n}=72)$ & $0.93(0.12-6.48)$ & 0.538 & $0.87(0.36-2.73)$ & \\
\hline Other variants $(n=24)$ & $0.85(0.15-4.84)$ & & $0.99(0.25-3.05)$ & \\
\hline \multicolumn{4}{|l|}{ BRAF } & \multirow{3}{*}{0.285} \\
\hline Wild type $(n=39)$ & $1.00(0.19-3.43)$ & 0.532 & $0.98(0.38-2.25)$ & \\
\hline $\operatorname{V600E}(n=37)$ & $0.93(0.22-6.48)$ & & $0.91(0.34-3.05)$ & \\
\hline \multicolumn{2}{|l|}{ Tumor size } & \multirow{3}{*}{0.781} & & \multirow{3}{*}{0.141} \\
\hline $\mathrm{T} 1-2(\mathrm{n}=41)$ & $0.94(0.12-1.96)$ & & $0.94(0.38-2.25)$ & \\
\hline T 3-4 (n=55) & $0.93(0.15-6.48)$ & & $0.91(0.25-3.05)$ & \\
\hline \multicolumn{3}{|l|}{ Lymph node metastases } & & \multirow{3}{*}{0.835} \\
\hline No $(n=57)$ & $0.85(0.12-6.48)$ & 0.296 & $0.93(0.25-2.25)$ & \\
\hline Yes $(n=39)$ & $0.99(0.19-4.84)$ & & $0.91(0.36-3.05)$ & \\
\hline \multicolumn{2}{|l|}{ TNM stage } & \multirow{3}{*}{0.425} & & \multirow{3}{*}{0.833} \\
\hline I-II (n=63) & $0.8(0.12-3.43)$ & & $0.86(0.36-2.73)$ & \\
\hline III-IV (n=33) & $0.96(0.15-6.48)$ & & $0.98(0.25-3.05)$ & \\
\hline \multicolumn{2}{|l|}{ Recurrences } & \multirow{3}{*}{0.057} & & \multirow{3}{*}{0.006} \\
\hline No $(n=63)$ & $1.04(0.15-6.48)$ & & $0.94(0.25-3.05)$ & \\
\hline Yes $(n=17)$ & $0.68(0.22-2.34)$ & & $0.63(0.36-1.6)$ & \\
\hline
\end{tabular}


A

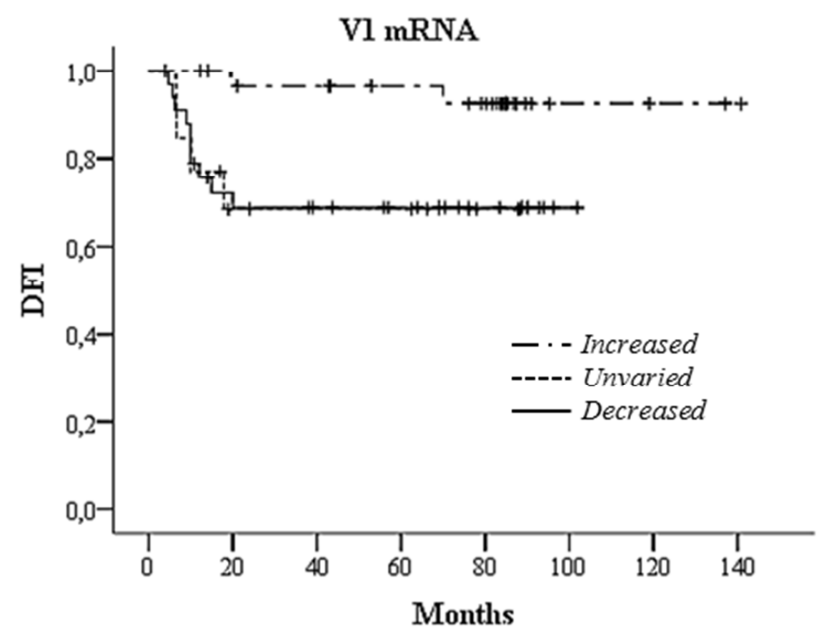

$\mathrm{C}$

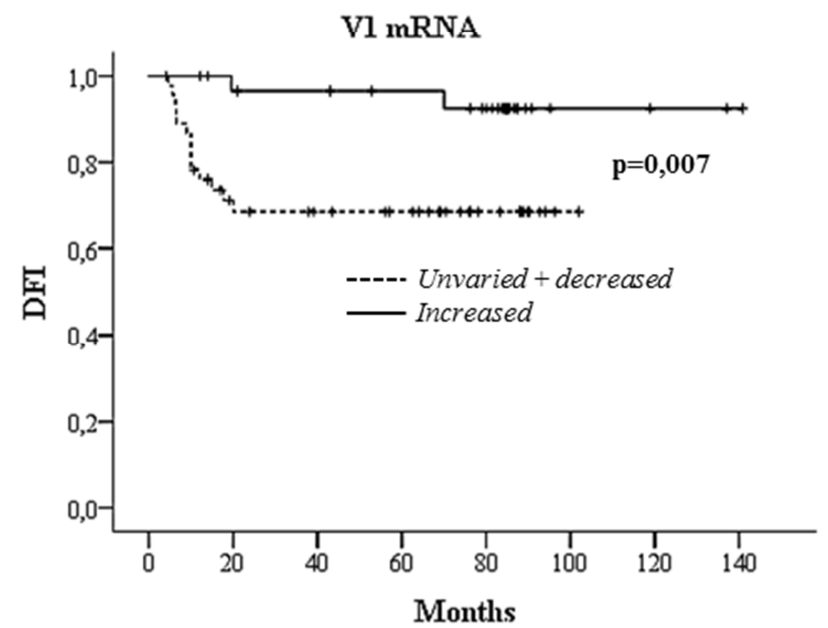

$\mathrm{B}$

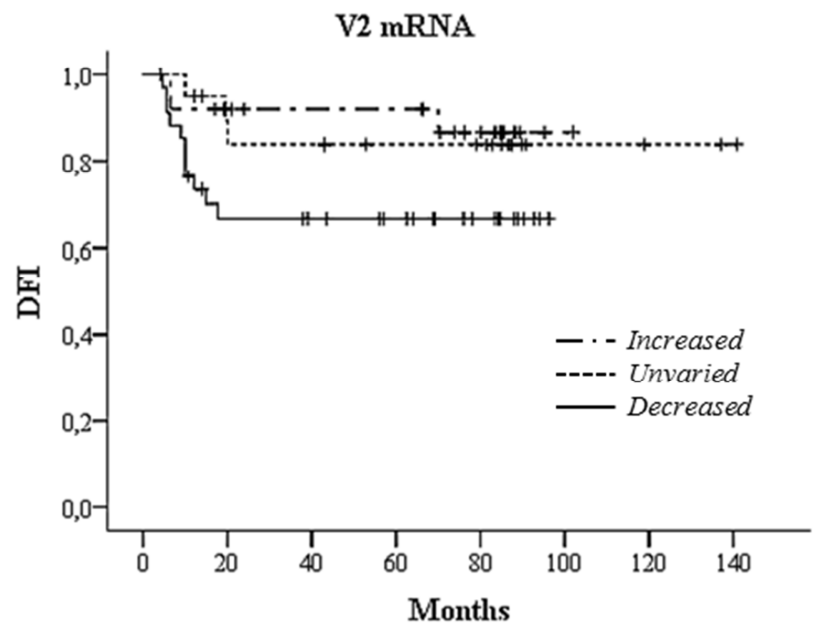

$\mathrm{D}$

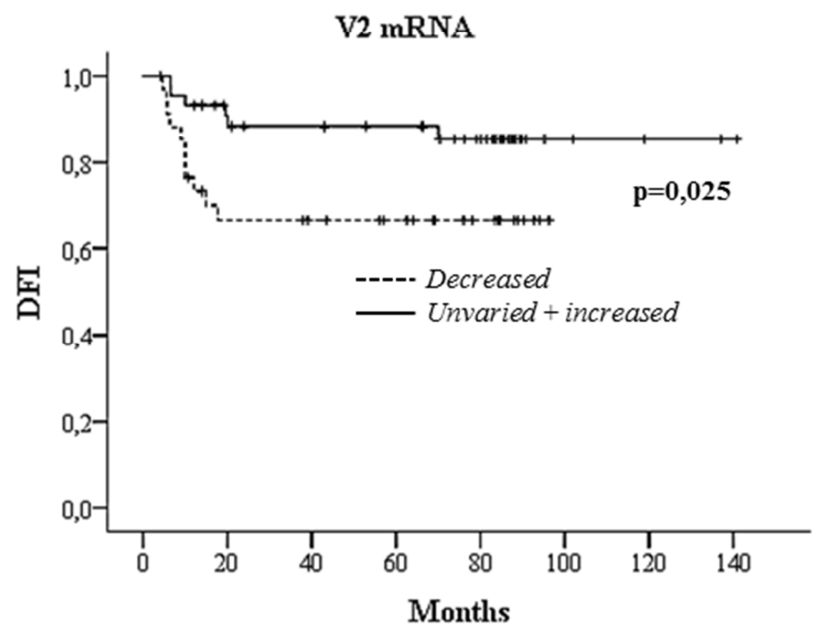

Figure 3: Levels of VHL mRNA variants and disease-free interval (DFI) in PTC patients. Kaplan-Mayer analysis combined with Mantel-Cox log-rank statistical test, performed on 80 PTC patients followed-up from 5 to 141 months. Expression values of V1 and V2 VHL variants were classified as increased (fold change $>1.2$ ), decreased (fold change $<0.8$ ) or unvaried $(0.8 \leq$ fold change $\leq 1.2$ ). 


\section{Discussion}

To date, relative few studies have attempted to investigate the effects of a deregulated $V H L$ expression in DTC evolution (The Cancer Genome Atlas Research Network, 2014; Stanojevic et al. 2015; Hinze et al. 2000; Hunt et al. 2003). Earlier immunohistochemical analyses demonstrated the presence of pVHL in normal thyroid follicular epithelium as well as in non-neoplastic lesions, and in DTC (Hinze et al. 2000). Intriguingly, an inverse correlation between VHL expression and tumor differentiation was found, the pVHL being diminished in poorly differentiated TC, and very weak or undetectable in the most deadly type of TC, the anaplastic carcinoma (Hinze et al. 2003). However, no correlation between pVHL and VEGF proteins could be observed, suggesting a HIF $\alpha$ independent role of pVHL in TC progression (Hinze et al. 2003). Although no loss-of-function mutations of VHL have been described so far in PTC, one study reported loss of heterozygosis (LOH) at the VHL gene in FTC (Hunt et al. 2003). These authors identified LOH in malignant but not in benign follicular tumors, and described a significant association between LOH and disease recurrence (Hunt et al. 2003). In PTC, no LOH specific for the VHL gene has been identified so far; however, different studies documented a variable LOH for the chromosomal region $3 p$ where the VHL gene is located (Grebe et al. 1997; Rodrigues-Serpa et al. 2003). In particular, Grebe and colleagues reported the presence of LOH on the chromosome $3 p$ in $28.5 \%$ of PTC analyzed, while Rodrigues-Serpa made the same observations in 40\% of PTC (Grebe et al. 1997; Rodrigues-Serpa et al. 2003). Since in our PTC series we found that both V1 and V2 mRNAs were downregulated in about $43 \%$ of cases, it may be speculated that haploinsufficiency is, at least in part, the cause of this reduction. Nevertheless, further studies will be required to prove this point.

More recently, Stanojevic and colleagues (2015) evaluated the status and expression of the $V H L$ gene on a case study of 264 patients with PTC. No somatic mutations or evidence of VHL downregulation via promoter hypermethylation were found. However, low VHL mRNA levels strongly associated with older patient's age, advanced clinical stage, classical PTC variant, and multifocality (Stanojevic et al. 2015). The authors noticed also a marginal influence of low VHL expression on disease-free interval (DFI) $(\mathrm{p}=0.0502)$.

Over the years, most of the studies regarding VHL expression have been accomplished without distinguishing between isoforms. However, as mentioned above, the absence of part of the $\beta$ domain (aa 114-154) in $\mathrm{pVHL}_{172}$ modifies the number of beta sheets in the structure, which is likely to cause altered protein activity and interactions (Schoenfeld et al. 1998). In our case study we sought to examine separately VHL isoforms in order to determine any differences in their expression profile that could be of relevance in thyroid tumor progression. Unfortunately, this approach implies the impossibility to discriminate isoforms at the protein level by means of 
immunohistochemistry, due to the lack of antibodies able to specifically identify the $\mathrm{VVHL}_{172}$. Therefore, we analyzed the mRNA levels of the two VHL splicing variants by means of specific primers. The results obtained indicate that the V1 mRNA variant is the most abundant one in almost all samples analyzed, and the median V1/V2 ratio do not change significantly between tumor and normal matched tissues. The expression of both V1 and V2 is deregulated in the majority of PTC tissues $(81.3 \%$ and $67.7 \%$, respectively), compared to their normal matched counterparts. Univariate analysis clearly showed the absence of correlation between the VHL mRNAs and patient's age, histological variant, tumor size, lymph node metastases and stage. Reduced V1 mRNA levels significantly associated with female gender, but the meaning of such association remains to be defined. The activating mutation V600E of the BRAF gene is frequently encountered in PTC where it has been associated with a more aggressive phenotype, thus we decided to investigate its effect on the expression of the two VHL mRNA variants. The statistical results showed, however, the lack of any influence of the $\mathrm{BRAF}^{\mathrm{V} 600 \mathrm{E}}$ mutation on VHL expression.

A significant association of low V2 mRNA levels with tumor recurrence was found, and a similar trend $(\mathrm{p}=0.057)$ appeared for the $\mathrm{V} 1$ variant. In agreement with this, multivariate analysis demonstrated that patients bearing increased levels of $V 1$ mRNA had a reduced risk of tumor recurrences. In addition, the output of Kaplan-Meier analysis evidenced a shorter DFI for patients with reduced level of the V2 mRNA in tumor tissues, and for patients with either unvaried or diminished V1 mRNAs. The protective effect of the $V H L$ gene in PTC patients is in line with its anti-oncogenic role extensively documented for kidney cancer.

The discrepancy between our observations and those reported by Stanojevic and colleagues (2015) may be explained by the fact that they analyzed $V H L$ transcripts without distinguishing the two splicing variants, and they adopted a different method of relative quantification based on the comparison of PTC samples with each other, rather than with the normal matched samples. Anyway, while taking into account the conflicting statistical results of the two studies, Stanojevic and colleagues pointed to an inverse correlation between VHL expression and PTC aggressive behaviour, essentially reflecting the overall indications emerged in our findings.

In conclusion, although the data here reported need to be confirmed by means of larger case-studies, they demonstrate that the expression of both VHL transcriptional variants is deregulated in the majority of PTC tissues. Their role(s) in PTC progression remains, however, to be clarified. 


\section{Author disclosure statement}

Authors declare that there is no conflict of interest that could be perceived as prejudicing the impartiality of the research reported.

\section{Funding}

This research did not receive any specific grant from funding agencies in the public, commercial, or not-for-profit sectors. 


\section{References}

Balamurugan, K., 2016. HIF-1 at the crossroads of hypoxia, inflammation, and cancer. Int. J. Cancer 138 (5), 1058-1066.

Baldini, E., Sorrenti, S., D'Armiento, E., Di Matteo, F.M., Catania, A., Ulisse, S., 2012. The urokinase plasminogen activating system in thyroid cancer: clinical implications. G. Chir. 33 (10), 305-310.

Barollo, S., Pennelli, G,, Vianello, F., Watutantrige Fernando, S., Negro, I., Merante Boschin, I., Pelizzo, M.R., Rugge, M., Mantero, F., Nacamulli, D., Girelli, M.E., Busnardo, B., Mian, C., 2010. BRAF in primary and recurrent papillary thyroid cancer: the relationship with (131)I and 2-[(18)F]fluoro-2-deoxy-D-glucose uptake ability. Eur. J. Endocrinol. 163 (4), 659-663.

Bonicalzi ME, Groulx I, de Paulsen N, Lee S. 2001. Role of exon 2-encoded beta -domain of the von Hippel-Lindau tumor suppressor protein. J Biol Chem 276:1407-1416.

Cassol, C., Mete, O., 2015. Endocrine manifestations of von Hippel-Lindau disease. Arch. Pathol. Lab. Med. 139 (2), 263-268.

Castagna, M.G., Maino, F., Cipri, C., Belardini, V., Theodoropoulou, A., Cevenini, G., Pacini, F., 2011. Delayed risk stratification, to include the response to initial treatment (surgery and radioiodine ablation), has better outcome predictivity in differentiated thyroid cancer patients. Eur. J. Endocrinol. 165 (3), 441-446.

Chesnel, F., Hascoet, P., Gagné, J.P., Couturier, A., Jouan, F., Poirier, G.G., Le Goff, C., Vigneau, C., Danger, Y., Verite, F., Le Goff, X., Arlot-Bonnemains, Y., 2015. The von HippelLindau tumour suppressor gene: uncovering the expression of the pVHL172 isoform. Br. J. Cancer 113 (2), 336-344.

Chomczynsky, P., Sacchi, P., 1987. Single step method of RNA isolation by guanidinium thiocyanate-phenol-chloroform extraction. Anal. Biochem. 162 (1), 156-159.

Davies, L., Welch, HG., 2006. Increasing incidence of thyroid cancer in the United States, 1973-2002. JAMA 295 (18), 2164-2167. 
Eustatia-Rutten CF, Corssmit EP, Biermasz NR, Pereira AM, Romijn JA, Smit JW. 2006. Survival and death causes in differentiated thyroid carcinoma. J Clin Endocrinol Metab 91:313319.

Gnarra JR, Tory K, Weng Y, Schmidt L, Wei MH, Li H, Latif F, Liu S, Chen F, Duh FM, Lubensky I, Duan DR, Florence C, Pozzatti R, Walther MM, Bander NH, Grossman HB, Brauch H, Pomer S, Brooks JD, Isaacs WB, Lerman MI, Zbar B, Linehan WM. 1994. Mutations of the VHL tumour suppressor gene in renal carcinoma. Nat Genet 7:85-90.

Gospodarowicz MK, Henson DE, Hutter RVP, O’Sullivan B, Sobin LH, Wittekind C. 2001. Prognostic factors in cancer. 2nd ed. New York: Wiley-Liss. 809 p.

Grebe SK, McIver B, Hay ID, Wu PS, Maciel LM, Drabkin HA, Goellner JR, Grant CS, Jenkins RB, Eberhardt NL. 1997. Frequent loss of heterozygosity on chromosomes $3 p$ and $17 p$ without VHL or p53 mutations suggests involvement of unidentified tumor suppressor genes in follicular thyroid carcinoma. J Clin Endocrinol Metab 82:3684-3691.

Handkiewicz-Junak D, Czarniecka A, Jarząb B. 2010. Molecular prognostic markers in papillary thyroid cancer: current status and future directions. Mol Cell Endocrinol 322:8-28.

Hedinger C, Williams ED, Sobin LH. 1989. The WHO histological classification of thyroid tumors: a commentary on the second edition. Cancer 63:908-911.

Hinze R, Boltze C, Meye A, Holzhausen HJ, Dralle H, Rath FW. 2000. Expression of the von Hippel-Lindau tumor suppressor gene in nonneoplastic and neoplastic lesions of the thyroid. Endocr Pathol 11:145-155.

Hunt JL, Yim JH, Tometsko M, Finkelstein SD, Swalsky P, Carty SE. 2003. Loss of heterozygosity of the VHL gene identifies malignancy and predicts death in follicular thyroid tumors. Surgery 134:1043-1048. 
Iliopoulus O, Ohh M, Kaelin JrWG. 1998. pVHL19 is a biological active product of the von Hippel-Lindau gene arising from internal translation inititation. Proc Natl Acad Sci USA 95:11661-11666.

Jemal A, Siegel R, Ward E, Hao Y, Xu J, Thun MJ. 2009. Cancer Statistics, 2009. Ca Cancer J Clin 59:225-249.

Kinder BK. 2003. Well differentiated thyroid cancer. Curr Opin Oncol 15:71-77.

Latif F, Tory K, Gnarra J, Yao M, Duh FM, Orcutt ML, Stackhouse T, Kuzmin I, Modi W, Geil L, Schmidt L, Zhou F, Li H, Hui Wei M, Chen F, Glenn G, Choyke P, Walther MM, Weng Y, Duan DSR, Dean M, Glava D, Richards FM, Crossey PA, Ferguson-Smith MA, Le Paslier D, Chumakov I, Cohen D, Chinault AC, Maher ER, Linehan WM, Zbar B, Lerman M. 1993. Identification of the von Hippel-Lindau disease tumor suppressor gene. Science 260:13171320.

Los M, Jansen GH, Kaelin WG, Lips CJ, Blijham GH, Voest EE. 1996. Expression pattern of the von Hippel-Lindau protein in human tissue. Lab Invest 75:231-238.

Maher ER, Neumann HP, Richard S. 2011. von hippel-Lindau disease: a clinical and scientific review. Eur J Hum Genet 19:617-623.

Nikiforov YE, Biddinger PW, Thompson LDR. 2009. Diagnostic pathology and molecular genetics of the thyroid. Philadelphia: Lippincott Williams \& Wilkins. 381p.

Pasieka JL. 2003. Anaplastic thyroid cancer. Curr Opin Oncol 15:78-83.

Passler C, Scheuba C, Prager G, Kaczirek K, Kaserer K, Zettinig G, Niederle B. 2004. Prognostic factors of papillary and follicular thyroid cancers: differences in an iodine-replete endemic goiter region. Endocr-Relat Cancer 11:131-139.

Patel KN, Shaha AR. 2006. Poorly differentiated and anaplastic thyroid cancer. Cancer Control 13:119-128. 
Richards FM, Schofield PN, Fleming S, Maher ER. 1996. Expression of the von Hippel-Lindau disease tumour suppressor gene during human embryogenesis. Hum Mol Genet 5:639-644.

Robinson CM, Ohh M. 2014. The multifaceted von Hippel-Lindau tumor suppressor protein. Febs Lett 588:2704-2711.

Rodrigues-Serpa A, Catarino A, Soares J. 2003. Loss of heterozygosity in follicular and papillary thyroid carcinomas. Cancer Genet Cytogenet 141:26-31.

Schoenfeld A, Davidowitz EJ, Burk RD. 1998. A second major native von Hippel-Lindau gene product, initiated from an internal translation start site, functions as a tumor suppressor. Proc Natl Acad Sci USA 95:8817-8822.

Stanojevic B, Saenko V, Todorovic L, Petrovic N, Nikolic D, Zivaljevic V, Paunovic I, Nakashima M, Yamashita S, Dzodic R. 2015. Low VHL mRNA expression is associated with more aggressive tumor features of papillary thyroid cancer. PloS One 9:e114511.

The Cancer Genome Atlas Research Network. 2014. Integrated Genomic Characterization of Papillary Thyroid Carcinoma. Cell 159:676-690.

Ulisse S, Baldini E, Sorrenti S, Barollo S, Gnessi L, Catania A, Pellizzo MR, Nardi F, Mian C, De Antoni E, D'Armiento M, Frati L. 2011. High expression of the urokinase plasminogen activator and its cognate receptor associates with advanced stages and reduced disease-free interval in papillary thyroid carcinoma. J Clin Endocrinol Metab 96:504-508.

Ulisse S, Baldini E, Sorrenti S, Barollo S, Prinzi N, Catania A, Nesca A, Gnessi L, Pelizzo MR, Mian C, De Vito C, Calvanese A, Palermo S, Persechino S, De Antoni E, D'Armiento M. 2012. In papillary thyroid carcinoma BRAFV600E is associated with increased expression of the urokinase plasminogen activator and its cognate receptor, but not with disease-free interval. Clin Endocrinol 77:780-786.

Vandesompele J, De Preter K, Pattyn F, Poppe B, De Paepe A, Speleman F. 2002. Accurate normalization of real-time quantitative RT-PCR data by geometric averaging of multiple internal control genes. Genome Biol 3:RESEARCH0034. 


\section{Highlights}

- Reduced expression of the VHL gene has been associated with more aggressive PTCs.

- Here we characterized the expression of the two VHL mRNA variants in PTC tissues.

- We showed that VHL gene expression is deregulated in the majority of PTC tissues.

- Of note is the protective role exerted by VHL transcripts against PTC recurrences. 